\title{
Mediterranean diet and metabolic syndrome: the evidence
}

\author{
Nancy Babio ${ }^{1,2}$, Mònica Bulló ${ }^{1,2}$ and Jordi Salas-Salvadó 1,2,* \\ 'Human Nutrition Unit, Department of Biochemistry and Biotechnology, Hospital Universitari de Sant Joan de \\ Reus, IISPV, Faculty of Medicine and Health Sciences, Rovira i Virgili University, Spain: ${ }^{2} \mathrm{CIBER}$ CB06/03 \\ Fisiopatología de la Obesidad y Nutrición, Instituto de Salud Carlos III, Spain
}

\section{Submitted $\mathbf{m} \mathbf{m}$}

\begin{abstract}
Background: The Mediterranean diet has long been related to a lower cardiovascular disease risk; however, more recent evidences also indicate that it has a favourable effect on adiposity and type 2 diabetes.

Design: Review of the available literature in relation to Mediterranean diet and metabolic syndrome.

Results: Several components of Mediterranean diet patterns have been inversely related with body mass index. They are considered to be modulators of insulin resistance, can exert beneficial effects on blood pressure, improve atherogenic dyslipidemia or attenuate the inflammatory burden associated with metabolic syndrome. Furthermore, a lower prevalence of metabolic syndrome has been associated with dietary patterns rich in fruits and vegetables, nuts, olive oil, legumes and fish, moderate in alcohol and low in red meat, processed meat, refined carbohydrates and whole-fat dairy products. Conclusions: There is much evidence suggesting that the Mediterranean diet could serve as an anti-inflammatory dietary pattern, which could help to fight diseases related to chronic inflammation, including metabolic syndrome.
\end{abstract}

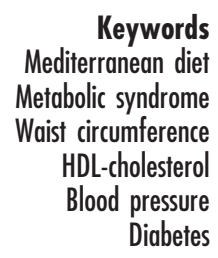

Metabolic syndrome (MetS) is considered to be a clustering of metabolic alterations conferring a high risk of developing type 2 diabetes (T2D), cardiovascular disease (CVD) and all-causes of mortality. Although the prevalence of MetS differs according to the criteria used to define it, in developed countries it seems to affect around $25 \%$ of the population ${ }^{(1-3)}$.

Since Reaven described MetS for the first time in 1988, diagnostic criteria have been systematically updated by expert groups ${ }^{(4-6)}$. However, despite various efforts, there is no general consensus regarding the definition of MetS.

Ethnic and national differences in the prevalence of MetS have been reported ${ }^{(7-9)}$. These differences cannot be explained by population genetics alone and may be more readily indicative of environmental influences, lifestyle and sociodemographic factors. Physical activity, smoking, low social class, low education level and low grade of chronic inflammation have been associated with an increased risk of $\operatorname{MetS}^{(10,11)}$. Diet may also be one of the most important factors determining MetS. Thus, the aim of the present paper is to analyse the effect of diet on MetS and its components. This review focuses on the possible relationship between the traditional Mediterranean diet (MedDiet) and MetS.

\section{Effect of the Mediterranean diet on adiposity}

Central adiposity, specifically visceral obesity, has been thought to be one of the key factors in the physiopathology of insulin resistance and all the other components of MetS. In fact, the International Diabetes Federation diagnostic criteria for MetS emphasise central obesity as the core measure $^{(6)}$. Waist circumference has been reported to be most specifically associated with cardiovascular risk ${ }^{(12)}$, as well as other components of MetS, including increased levels of some inflammatory and endothelial markers ${ }^{(13)}$, blood pressure, glucose and triglycerides concentrations ${ }^{(14)}$, and low HDL-cholesterol levels ${ }^{(15)}$.

Several components of the MedDiet have been inversely associated with BMI or waist circumference. This is the case for whole grain and fibre. In the Multi-ethnic Insulin Resistance Atherosclerosis Study, the dark bread pattern derived from cluster analysis was associated with higher fibre consumption relative to total energy and with lower waist circumference ${ }^{(16)}$. Wirfalt et $a l^{(17)}$ also used a cross-sectional design and observed that a high dietary fibre intake was related to lower central adiposity. This is consistent with some prospective studies showing that high fibre intake is associated with a lower increase in body weight or central adiposity. For example, in the Health Professionals Follow-up Study, patients in the higher quintile of change in fibre intake have a lower risk of total body weight increase during the 8 years of follow-up ${ }^{(18)}$. Also, in the CARDIA (Coronary Artery Risk Development In young Adults) Study, total fibre consumption was independently and inversely associated with weight-gain and waist-circumference increases in both white and black men and women ${ }^{(19)}$. Finally, in the 
Nurses' Health Study, weight gain was inversely associated with the intake of high-fibre, whole grain foods but positively related to the intake of refined grain, which indicated the importance of distinguishing whole and refined-grain products to aid in weight control ${ }^{(20)}$. Several mechanisms have been suggested in order to explain the protective effect of fibre on weight gain ${ }^{(21)}$, however, few randomised clinical studies have demonstrated beneficial effects on total body weight gain or loss after consuming high fibre diets or supplements ${ }^{(22)}$.

The MedDiet is a high-fat, high-unsaturated fat food pattern because olive oil is used abundantly as a culinary fat and for dressings, which facilitates the intake of substantial quantities of vegetables. Some epidemiological studies have analysed the effect of the total amount of fat consumption relative to carbohydrates on body weight and abdominal adiposity, without clear and consistent results. For example, in the Nurses' Health Study, one of the largest cohort studies, there was a weak positive association between total fat intake and weight gain ${ }^{(23)}$. However, several studies have demonstrated that the type of fat is more important than the amount consumed in terms of body weight and adiposity regulation. Monounsaturated fatty acids (MUFA) and polyunsaturated fatty acids (PUFA) have been shown to be more easily oxidised than saturated fatty acids (SFA). This is consistent with some epidemiological studies. For example, in the Nurses' Health Study, animal fat, SFA and trans fatty acid (TFA) intake have been positively associated with weight gain, whereas MUFA and PUFA were not associated $^{(23)}$. In the Health Professional Cohort Study, replacing PUFA with SFA or TFA was also associated with a significant increase in waist-circumference gain over 9 years ${ }^{(24)}$.

Recently, the SUN (Seguimiento Universidad de Navarra) Project has specifically evaluated the possible association between olive oil consumption and the likelihood of weight gain or the incidence of overweight or obesity in a large Mediterranean cohort of 7368, who were followed for a median period of 28.5 months ${ }^{(25)}$. In this study, baseline consumption of olive oil was associated with a non-significant lower likelihood of weight gain. For participants with a higher baseline consumption of olive oil, whose olive oil consumption also increased during follow-up, the authors found a slightly increased but non-significant risk of becoming overweight.

Nuts are another high-unsaturated fat food commonly consumed in the MedDiet. Evidence from epidemiological and clinical studies suggests that regular nut intake might have a positive impact on adiposity ${ }^{(25)}$, insulin resistance and other metabolic disturbances linked to the MetS. Consumption of nuts has been associated with satiety, increased thermogenesis, fat malabsorption and lower adiposity ${ }^{(26)}$.

Finally, fruit and vegetable consumption has been demonstrated to protect against weight gain and obesity. In the Nurses' Health Study, participants with the largest increase in fruit and vegetable intake had a $24 \%$ lower risk of becoming obese compared with those who had the largest decrease in intake after adjustment for several confounding factors ${ }^{(27)}$. Also recently, Vioque et al. ${ }^{(28)}$ have demonstrated that dietary patterns associated with a high intake of fruit and vegetables in a Mediterranean population may reduce long-term risk of subsequent weight gain and obesity among Spanish adults.

In contrast, fast food and unhealthy dietary patterns have been consistently associated with a higher risk of weight gain and obesity ${ }^{(29,30)}$. A recently published systematic review shows that frequent consumption of sugar-sweetened beverages is associated with weight gain and obesity ${ }^{(31)}$. Although more research is needed, there is sufficient evidence for public health strategies to discourage the consumption of fast food and sugary drinks as part of a healthy lifestyle.

Recently, the EPIC (European Prospective Investigation into Cancer and Nutrition) Study suggested that adhering to the MedDiet was not associated with becoming overweight in normal-weight subjects, suggesting that promoting eating habits consistent with traditional MedDiet patterns may play a useful part in efforts to combat obesity ${ }^{(32)}$.

\section{Effect of the Mediterranean diet on insulin resistance and diabetes}

Many components of the MedDiet have been considered to be important in the modulation of insulin resistance, especially the type of dietary fat and the glycaemic index of the diet.

There is little evidence that low-fat, high-carbohydrate diets improve insulin sensitivity ${ }^{(33)}$. In developed countries, low-fat diets are usually rich in refined carbohydrates, which increase plasma glucose and insulin concentrations. However, diets rich in whole grains and dietary fibre have been associated with lower plasma insulin concentrations ${ }^{(19,34)}$ and inversely related to measures of insulin resistance ${ }^{(34,35)}$ and improved insulin sensitivity ${ }^{(16)}$.

The Nurses' Health Study reports an increased incidence of T2D in those participants consuming a diet with a higher glycaemic load, especially if consumed in combination with a low intake of cereal fibre ${ }^{(36)}$. These results were confirmed in the Health Professionals Follow-up Study ${ }^{(37)}$, but not in the Iowa Women's Health Study ${ }^{(38)}$. In that study, glycaemic load was not associated with the risk of diabetes, although the authors found an inverse relation between fibre intake and the incidence of diabetes. However, in a recent Cochrane review, it was concluded that the evidence from prospective cohort trials is considered to be too weak to be able to draw a definite conclusion about the preventive effect of whole grain foods on the development of T2D ${ }^{(39)}$.

The type of fat consumed is probably a more important dietary factor determining the risk of developing insulin resistance and diabetes. Some epidemiological evidence suggests that dietary SFA and TFA are related to a higher 
risk of developing insulin resistance and diabetes, whereas dietary MUFA and PUFA protect against these conditions. Laaksonen et al. ${ }^{(40)}$ demonstrated an important relationship between serum fatty acid composition, a biomarker of habitual fat intake, and the development of diabetes. Baseline serum SFA levels were higher and PUFA levels were lower in men who developed insulin resistance in the 4 years of follow-up.

Some dietary intervention studies have demonstrated that substituting SFA for MUFA alters fatty acid composition and improves insulin sensitivity ${ }^{(41)}$. In the KANWU (Kopio, Aahhus, Naples, Wollongon and Uppsala) Study, it has also been demonstrated that a change in the proportions of dietary fatty acid, decreasing SFA and increasing MUFA, improves insulin sensitivity ${ }^{(42)}$.

Some epidemiological studies have found PUFA to be inversely associated with insulin levels ${ }^{(43)}$, and others have reported a positive association ${ }^{(44)}$. A prospective cohort study ${ }^{(45)}$ found that the frequency of nut consumption, which is rich in unsaturated fatty acids, had a substantial and highly significant inverse association with risk of T2D, independently of some confounding factors. However, the substitution of SFA for PUFA can favourably affect insulin sensitivity. In hyperlipidemic patients, a diet rich in PUFA was shown to induce, more favourably, glucose tolerance than a diet high in SFA, especially in hypertriglyceridemic patients ${ }^{(46)}$.

Some prospective studies have attempted to evaluate the relationship between the consumption of $n-3$ PUFA, or fish, and the risk of diabetes. Three studies demonstrated that a higher intake had a beneficial effect on the risk of diabetes or impaired glucose tolerance, whereas one study did not ${ }^{(47,48)}$. Short-term interventional trials have failed to demonstrate that consumption of $n$ - 3 fatty acids has a beneficial effect on insulin sensitivity in diabetic or non-diabetic patients. Long-term intervention studies have also shown no significant improvements in insulin sensitivity in healthy and diabetic patients ${ }^{(49)}$.

There is some evidence that meat and processed meat have unfavourable effects on glucose metabolism; however, this observation is derived from epidemiological studies only ${ }^{(50,51)}$.

\section{Effect of the MedDiet on atherogenic dyslipidemia}

Atherogenic dyslipidemia is characterised by an increase in the LDL-cholesterol levels and triglycerides, and is frequently associated with MetS. If in recent years dietary interventions were focused on reducing the LDL-cholesterol levels, it is now recognised that dietary and non-dietary strategies to increase and decrease HDL-cholesterol and triglyceride concentrations, respectively, have become important targets for preventing and treating MetS.

Several studies have shown that low-fat/high-carbohydrate diets decrease HDL-cholesterol concentrations ${ }^{(52-54)}$ and this appears to be independent of the PUFA content ${ }^{(55)}$. It has been suggested that the effects of high-carbohydrate/low-fat diets on triglycerides and HDL-cholesterol levels are transient, particularly after ad libitum intake of low-fat diets. However, after changing dietary fat, it has been shown that changes in HDLcholesterol and in triglycerides levels are sustained for periods of several months ${ }^{(56)}$ or even up to 1 year ${ }^{(57)}$. For these reasons low-fat/high-carbohydrate diets were not considered ideal for MetS. On the contrary, low-carbohydrate diets were associated with a decrease in triglycerides and an increase in HDL-cholesterol levels ${ }^{(58)}$, although the type of carbohydrate and fat in these diets can influence the plasma lipoprotein profile ${ }^{(22)}$.

The type of carbohydrate in the low-fat diet may be important both for reducing HDL-cholesterol and increasing plasma triacylglycerol. In healthy free-living men, Turley et al. ${ }^{(59)}$ found that replacing SFA with carbohydrates from grains, vegetables, legumes and fruit reduced total and LDL-cholesterol, and had only a minor effect on HDL-cholesterol and triglycerides. Frost et al. ${ }^{(60)}$ suggested that there is a connection between the glycaemic index and the level of HDL-cholesterol. Thus, intake of carbohydrates with a low glycaemic index results in smaller HDL-cholesterol reduction than intake of carbohydrates with a higher index ${ }^{(61)}$. On the contrary, the intake of carbohydrates with a high glycaemic index and glycaemic load was inversely associated with HDLcholesterol concentrations and positively associated with fasting triglycerides. Nevertheless, interventional studies have reported conflicting results regarding the effect of the glycaemic index on dyslipidemia ${ }^{(62)}$.

The $n$ - 3 fatty acids may also ameliorate the atherogenic lipid profile. For example, native Alaskan populations that eat a diet rich in $n-3$ PUFA have high HDL-cholesterol levels ${ }^{(63)}$. Also, $n-3$ fatty acid intake was associated with lower levels of triglycerides, reduced endothelial activation and other factors associated with $\mathrm{MetS}^{(64)}$. In addition, dietary omega-3 PUFAs are known to reduce triglyceride levels in obese people and patients with hypertriglyceridemia ${ }^{(65)}$.

Finally, moderate alcohol consumption raises HDLcholesterol levels ${ }^{(66)}$. A meta-analysis indicated that the consumption of $30 \mathrm{~g}$ of alcohol/d increases HDLcholesterol levels by a mean of $4 \mathrm{mg} / \mathrm{dl}$, irrespective of the kind of alcohol consumed ${ }^{(67)}$. Thus, the moderate consumption of wine frequently observed in Mediterranean populations, may protect against coronary disease through this mechanism.

Therefore, a diet rich in fibre, $n$-3 PUFA ( $n-3$ rich oils, cold water fish, walnuts) and MUFA, with limited carbohydrates that contribute to a high glycaemic load (such as those found in ready-to-eat cereals, potatoes, white bread and snack foods), is recommended to increase serum HDL-cholesterol levels and decrease triglycerides. 


\section{Effect of the Mediterranean diet on hypertension}

There is no doubt about the role that hypertension has as a cardiovascular risk factor, and the improvement in blood pressure that can be achieved through diet and lifestyle changes. Several studies have supported the beneficial effect on blood pressure that some nutritional strategies have (weight reduction, low intake of sodium and alcohol, high intake of vegetables and fruits).

Several minerals, such as sodium, magnesium, potassium and calcium, in the diet have been implicated in modulating blood pressure. A meta-analysis of randomised trials indicated that a reduction in sodium and an increase in potassium consumption lowers blood pressure in normotensive and hypertensive individuals ${ }^{(68,69)}$.

Some studies suggest that the beneficial effect of magnesium on blood pressure ${ }^{(70)}$ might be due to its endothelial vasodilator effect ${ }^{(71)}$. However, in a metaanalysis of randomised clinical trials, magnesium supplementation resulted in only a small dose-dependent reduction in blood pressure levels ${ }^{(72)}$. Likewise, a recent systematic review of twelve randomised controlled clinical trials did not report any clear beneficial effects of magnesium supplementation on blood pressure ${ }^{(73)}$. Both meta-analyses concluded that better quality double-blind placebo-controlled trials, that are also larger and longer, would be necessary to confirm this relationship.

Several epidemiological and interventional studies suggest that calcium is also largely implicated in modulating blood pressure. A meta-analysis of twenty-two randomised clinical trials showed a small but significant reduction in the systolic blood pressure through calcium supplementation in subjects with or without hypertension $^{(74)}$. However, because of the small observed effect of calcium, the authors concluded that there is insufficient evidence to recommend systematic calcium supplementation for preventing hypertension.

More consistent results were observed in relation to the effect of low-fat dairy products on hypertension. For example, in the SUN cohort, a 50\% reduction in the incident cases of hypertension was observed in individuals with a high consumption of low-fat dairy products. Interestingly, this was not described in the case of whole-fat dairy products, suggesting that the quantity and type of fat content could determine the beneficial effect ${ }^{(75)}$. There is some evidence suggesting that saturated fats are hypertensive compared to vegetable unsaturated fat, however, this hypothesis need to be confirmed ${ }^{(76)}$. Other prospective studies performed on overweight subjects ${ }^{(50)}$ and high cardiovascular risk individuals ${ }^{(76)}$ support the relationship between low-fat dairy product intake and low blood pressure. The evidence of protection deriving from low-fat dairy products could also be attributed to the nutritional composition of these products. Low-fat dairy products are rich in potassium, magnesium, calcium and some milk proteinderived peptides with established hypotensive properties ${ }^{(77)}$.
The most important evidence regarding the beneficial effect of diet on blood pressure is the DASH (Dietary Approaches to Stop Hypertension) Study. The overall effects on blood pressure observed by the DASH diet have been attributed to the whole dietary pattern, which was rich in fruit, vegetables, low-fat dairy products, and had reduced amounts of saturated and total fats and cholesterol ${ }^{(78)}$. More recently, Lien et al. ${ }^{(79)}$ showed a significant reduction in systolic blood pressure in subjects with MetS who were treated with the dietary DASH pattern associated with an intensive behavioural lifestyle intervention.

The MedDiet shares many of the characteristics of the DASH diet, for example, both are rich in vegetables and fruit. Several epidemiological studies have described an inverse association between MedDiet adherence and blood pressure ${ }^{(2,80,81)}$. Other components of the MedDiet could exert beneficial effects on blood pressure; this is the case with olive oil and wine. In the EPIC Study, olive oil, vegetables and fruits were the most important factors explaining low blood pressure levels ${ }^{(80)}$. In the SUN Study, olive oil consumption was also associated with lower risk of developing hypertension but only among men ${ }^{(82)}$. Also, two interventional studies have demonstrated that a diet rich in MUFA is more capable of reducing blood pressure compared to a diet rich in $\mathrm{SFA}^{(83)}$ and, unlike a low-fat, carbohydrate-rich diet, has no deleterious effect on blood pressure in normotensive subjects ${ }^{(84)}$. A reduction in the use of hypertensive medication was also observed after intake of a diet rich in olive oil, compared to a high PUFA diet ${ }^{(85)}$. The mechanism explaining how olive oil modulates blood pressure is still unknown.

The relationship between alcohol consumption and hypertension remains controversial. The beneficial effect is attributed mainly to red wine, because it is rich in some polyphenols that exert an endothelial vasorelaxing action $^{(86)}$. Some cross-sectional epidemiological studies have observed an inverse association between red wine consumption and blood pressure. In those studies, the association was not found for other alcoholic beverages $^{(87,88)}$. However, in a clinical trial, Zilkens et al. ${ }^{(89)}$ did not show any blood pressure effect after consuming red wine or de-alcoholised red wine.

\section{Effect of the Mediterranean diet on the inflammation and oxidation}

Several compounds of MetS are related to inflammatory abnormalities, suggesting that the mechanism underlying this syndrome could be a chronic low-grade inflammatory and oxidative state. It is well known that inflammatory cytokines induce insulin resistance in adipose tissue and muscle. Adipose tissue in obesity does indeed overproduce cytokines, and several cytokines such as 
C-reactive protein (CRP) and interleukin-6 (IL-6) have proven to be strong predictors of both diabetes and cardiovascular disease (CVD) in prospective cohort studies $^{(90,91)}$. Nevertheless, although different studies report higher levels of inflammatory or oxidative markers in MetS subjects, none of the current definitions consider inflammation or oxidation to be criteria for defining the syndrome. Results from the West of Scotland Coronary Prevention Study (WOSCOPS) ${ }^{(92)}$, the Women's Health Study (WHS) ${ }^{(93)}$ and the Framingham Offspring Study ${ }^{(94)}$ suggest that CRP adds clinically important prognostic information concerning MetS and cardiovascular risk. However, contradictory results were recently found in a prospective study on more than 173000 subjects from the Nurses' Health Study and the Health Professionals Follow-up Study where most of the inflammatory markers did not increase the relative risk of CVD beyond MetS. Only CRP and sICAM (soluble intercellular adhesion molecule) in men remained independently predictive of CHD when MetS status was taken into account ${ }^{(95)}$.

Among other strategies, diet could be one of the most important factors in treating MetS by modulating inflammation and oxidation ${ }^{(96-98)}$. Thus, recent studies deal specifically with adherence to the MedDiet and its association with inflammatory or oxidative mechanisms. The first study was published in 2004 by Crhysohoou et al. ${ }^{(99)}$ on more than 3000 subjects from the ATTICA Study, showing that those patients in the highest tertile of the diet score had lower levels of CRP, IL-6 or fibrinogen. Similar results on inflammatory markers were observed in a small group of patients with MetS who followed a MedDiet for 2 years, while endothelial dysfunction assessed with the L-arginine test improved ${ }^{(100)}$. This study reported a $48 \%$ net reduction in the prevalence of MetS after 2 years. More recently, it has been demonstrated that the association between the adherence to a MedDiet and systemic inflammation is independent of sharing environmental and genetic factors ${ }^{(101)}$. However, no effect of the MedDiet on inflammatory markers was observed in patients with coronary disease ${ }^{(102)}$. Until now, the Prevención con Dieta Mediterránea (PREDIMED) Study is the only study to have evaluated the effect of the MedDiet in patients on primary cardiovascular prevention and it showed a significant improvement in inflammatory and endothelial markers ${ }^{(103)}$. Moreover, in a subgroup of subjects from the PREDIMED cohort, oxidised LDL decreased significantly after 3 months on MedDiet ${ }^{(104)}$.

To date, intensive lifestyle interventions seem to work better than drugs in reducing the prevalence of MetS ${ }^{(105)}$. The MedDiet pattern is rich in virgin olive oil, nuts, vegetables, fruits, legumes and fish and is thus a good source of inflammation and oxidation modulator compounds such as MUFA and PUFA, dietary fibre or phytochemicals. This makes it a good approach for preventing MetS and CVD.

\section{Healthy and unhealthy dietary patterns and metabolic syndrome}

Dietary pattern analysis is used as an alternative and complementary approach to the individual analysis of nutrients and foods. Dietary patterns better reflect general eating behaviour, support the simple analysis of intake and allow the potential combined effect of overall $\operatorname{diet}^{(106)}$ on the risk of chronic diseases to be examined.

Although several epidemiological studies have evaluated the relationship between dietary pattern and some features of MetS ${ }^{(17,107-110)}$, in recent years there has been growing interest in examining the association between dietary patterns and MetS ${ }^{(2,100,111-116)}$.

A cross-sectional study by Williams et al. ${ }^{(116)}$ observed a negative relationship between higher scores of adherence to a healthy dietary pattern and central obesity, fasting plasma glucose and plasma triglycerides, and a positive association with plasma HDL-cholesterol. In this study, using principal component analysis, four dietary patterns were identified. Component 1 was the healthiest dietary pattern and was characterised by frequent intakes of salad, green vegetables and fruits, pasta or rice and low intake of fried foods, processed meat, fried fish, potatoes and snacks. It appears to protect against MetS ${ }^{(116)}$. Recently, a larger cross-sectional survey, also using principal components analysis, extracted three dietary patterns: the healthful food pattern, the highglycaemic index and the high-fat dietary pattern, and the alcohol intake pattern. Together these explained $56 \%$ of the variance in the dietary intake ${ }^{(115)}$. After adjusting for several confounders, the healthful food pattern, which included cereals, fish, legumes, vegetables and fruit (all of them components of the traditional MedDiet), was inversely associated with waist circumference, blood pressure, triglycerides, and positively associated with HDL-cholesterol levels, all known components of MetS. Furthermore, the healthful food pattern was associated with a $13 \%$ lower likelihood of having MetS. On the contrary, the high-glycaemic index/high-fat dietary pattern, mainly characterised as rich in meat, meat products and potatoes, was associated with a higher waist circumference, lower HDL-cholesterol levels and with a $21 \%$ higher likelihood of having MetS.

Recently, Esmaillzadeh et al..$^{(113)}$ - in 486 female teachers in Tehran - observed that a healthy dietary pattern (high in fruits, tomatoes, poultry, legumes, cruciferous and green vegetables, other vegetables, tea, fruit juices and whole grains) was associated with a significantly lower risk of having MetS. The same relationship was observed for each MetS component and after adjusting for several possible confounders. In the same study, women in the highest quintile of adscription to a Western dietary pattern (high in refined grains, red meat, butter, processed meat, high-fat dairy products, sweets and desserts, pizza, potatoes, eggs, hydrogenated fats, soft drinks and low in other vegetables and low-fat dairy products) had significantly greater odds of developing MetS. Likewise, in 
the Atherosclerosis Risk in Communities cohort, the subjects in the top quintile of adherence to the Western dietary pattern have an 18\% greater risk of developing MetS compared with those in the lowest quintiles. Contrary to other studies these authors did not find any significant association between a prudent dietary pattern and the incidence of $\mathrm{MetS}^{(117)}$. Some dietary intervention studies also support the beneficial effects of the DASH dietary pattern on the prevalence and the features of $\operatorname{MetS}^{(118)}$.

Several authors have also assessed the relationship between dietary patterns and some features of MetS. In a study using a large cohort during 14 years of followup $^{(51,110)}$, the prudent pattern characterised by high intake of fruits, vegetables, whole grains, fish, poultry and low-fat dairy products was modestly associated with a lower relative risk of having T2D. In contrast, stronger results were observed between the Western dietary pattern (characterised mainly by red or processed meats) and a higher increase relative risk of T2D.

Hyperinsulinaemia was also more prevalent in women having a food pattern characterised by a high intake of refined bread and less prevalent in those taking a milk-fat pattern $^{(17)}$. In men of the same cohort, a strong positive association was observed between hyperglycaemia and a dietary pattern characterised by high consumption of refined bread, cheese, cakes and alcoholic beverages. In relation to the hypertriglyceridemia, a cross-sectional study showed that a pattern high in reduced-fat dairy products, cereal, fruit, fibre (derived by factor or cluster analysis) was inversely associated to the triacylglycerol concentrations ${ }^{(108)}$.

Few authors have studied the relationship between some dietary patterns and blood pressure. In this context, no association between some identified dietary patterns and hypertension was observed by Wirfält et al. ${ }^{(17)}$. However, in a cross-sectional study of 19750 women and men, the cosmopolitan dietary pattern, characterised by a high intake of fried vegetables, salad, rice, chicken, fish and wine, was associated with lower blood pressure levels. In contrast, the traditional pattern characterised by a high intake of red meat and potatoes and low intake of low-fat dairy and fruits, was related to higher blood pressure ${ }^{(119)}$.

Some authors suggest that women, non-smokers ${ }^{(116)}$ and physically active subjects ${ }^{(113-115,119)}$ with a higher educational level ${ }^{(119)}$ have a healthier dietary pattern in general. For this reason, when analysing the relationship between the adscription to a dietary pattern and the presence or incidence of MetS, it is important to adjust for these possible confounders.

\section{Mediterranean diet and metabolic syndrome: the evidence}

There are few epidemiological studies analysing the relationship between adherence to the Mediterranean dietary pattern and MetS. To measure the Mediterranean dietary pattern the authors have used several dietary quality indices. Thus, in these studies the authors have used different questionnaires to assess the frequency of consumption of typically served foods in the traditional MedDiet (olive oil, fruit, vegetables, legumes, fish, wine) and also the intake of those food that are not part of this dietary pattern (whole-fat dairy products, red meat and refined carbohydrates).

In a cross-sectional study of 578 adults from the Canary Islands, Álvarez-León et $a l^{(2)}$ found no relationship between following the MedDiet and prevalence of MetS. However, subjects in the third tertile of adherence had a $70 \%$ lower prevalence of the blood pressure MetS criteria and 2.5 times more prevalence of the glycaemia criteria compared to the first tertile of adherence. In the same study, some components of the traditional MedDiet (wine, fruit, vegetable and cereals) showed a protective effect on the MS and its components.

Apart from the cross-sectional study of Alvarez-León et $a l^{(2)}$ who did not find relationship between the adherence to the MedDiet pattern and prevalence of MetS, other studies that have analysed this relationship support the beneficial effect of the Mediterranean dietary pattern on MetS. For example, in a cross-sectional survey of 1128 men and 1154 adult women from an urban area in Greece (the ATTICA Study), Panagiotakos et al. ${ }^{(115)}$ showed that adherence to this dietary pattern was associated with $20 \%$ lower odds of having MetS, irrespective of age, gender, physical activity status, lipids and blood pressure levels. Recently, we have also observed an inverse relationship between the score of adherence to the MedDiet and the prevalence of MetS in a cross-sectional study of a cohort of 808 old participants at high cardiovascular risk from the PREDIMED Study. Participants in the higher quartile of adherence to the MedDiet have a $56 \%$ lower risk of having MetS compared to those participants with a lower adherence $^{(111)}$.

This relationship was also analysed in the prospective study cohort SUN. After a 6-year follow-up of 3497 Spanish university participants, the authors observed that subjects who had the higher adherence score to the MedDiet pattern had the lower cumulative incidence of $\operatorname{MetS}^{(114)}$.

To the best of our knowledge, only two clinical trials have studied the effect of the traditional MedDiet on MetS. Esposito et al. $^{(100)}$ showed that a Mediterraneanstyle diet seems effective in reducing the prevalence of the MetS and its associated cardiovascular risk (they give instructions about increasing daily consumption of whole grains, vegetables, fruits, nuts and olive oil). Particularly, at the end of 2 years of follow-up, $44 \%$ patients in the intervention group still had features of MetS compared to $87 \%$ patients in the control group (who received a cardiac-prudent diet with fat intake of less than $30 \%$ ). This may lead to a $51 \%$ net risk reduction of having MetS due to the MedDiet intervention. Of particular note is the fact that energy intake was reduced, especially in the MedDiet 
intervention arm, and substantial weight loss was achieved. However, the higher percentage MetS resolution in the MedDiet group remained after adjusting for the effect of weight loss produced.

An ad libitum (without energy restriction), high-fat MedDiet, as traditionally followed in the Mediterranean countries, has not been tested for effects on MetS. Therefore, within the PREDIMED study, we compared the effects of two high-fat MedDiets on MetS after 1 year, one supplemented with virgin olive oil (VOO) and one supplemented with mixed nuts, with advice on a low-fat diet in volunteers at high risk for CVD, all diets being ad libitum. The PREDIMED study is a large, parallel group, multicenter, controlled clinical trial that aims to assess the effects of the traditional MedDiet on the primary prevention of CVD. At baseline, $61 \cdot 4 \%$ of participants met the criteria for MetS. After 1 year, prevalence was reduced by $6.7 \%, 13.7 \%$ and $2.0 \%$ in the MedDiet + VOO, MedDiet + Nuts, and Control diet groups, respectively. However, incident MetS rates were not significantly different among groups (22.9\%, $17 \cdot 9 \%$ and $23.4 \%$, respectively). After adjustment for gender, age, baseline obesity status and weight changes, the OR for reversion of MetS were $1 \cdot 3(95 \%$ CI $0 \cdot 8,2 \cdot 1)$ for the MedDiet + VOO and $1.7(95 \%$ CI $1 \cdot 1,2 \cdot 6)$ for the MedDiet + Nuts, compared with the Control diet. We concluded that a nonenergy-restricted traditional MedDiet enriched with nuts is a useful tool in the lifestyle management of MetS ${ }^{(112)}$.

Nutritional recommendations are targeted at the whole population, although it is clear that the responses to diet are largely heterogeneous due to inter-individual variations related to genetic determinants. In 2003, the MediRIVAGE Study (Mediterranean diet, Cardiovascular Risk and Gene Polymorphism) was designed and its secondary aim was to evaluate how the response to diet can be modulated by polymorphisms related to lipoprotein metabolism and homeostasis ${ }^{(120)}$. After 3 months of nutritional intervention, initial results derived from this study reported a clear interaction between the MTTP$493 \mathrm{G} / \mathrm{T}$ variation and the magnitude in the response of diet. Men homozygous for the allele T showed a marked improvement of biological markers for CVD in comparison to the other genotypes. In the case of the Ala54Thr polymorphism at the FABP2 (fatty acid binding protein 2), a decrease was only observed in apo B in the Thr/Thr population ${ }^{(121)}$. Whether other genes and their polymorphism could interact with diet and lead to a differential cardiovascular risk remains to be analysed.

In summary, these findings indicate that a healthy dietary pattern mainly characterised by high consumption of vegetables, fruits, nuts, olive oil, legumes and fish, moderate in alcohol and low in red meat, processed meat, refined carbohydrates and whole-fat dairy products is beneficial for people at higher risk of MetS or individuals with established MetS. Dietary intervention in this way may reduce cardiovascular risk in persons with MetS.

\section{Acknowledgements}

The present study was funded by the Spanish Ministry of Health (Instituto de Salud Carlos III, Thematic Network RTIC RD06/0045, Fondo de Investigaciones Sanitarias, PI04/1828 and PI05/1839), CYCYT AGL2005-0365 and Public Health Division of the Department of Health of the Autonomous Government of Catalonia. Conflicts of interests are as follows: J.S.S. is an unpaid member of the Scientific Advisory Board of the International Nut Council. N.B. and M.B. have no conflict of interest to declare. All the authors have participated in the redaction of the manuscript. The authors would like to thank Carles Munné-Cuevas (Human Nutrition Unit, URV) for the administrative and technical support provided.

\section{References}

1. Ford ES, Giles WH \& Mokdad AH (2004) Increasing prevalence of the metabolic syndrome among US adults. Diabetes Care 27, 2444-2449.

2. Alvarez Leon EE, Ribas Barba L \& Serra Majem L (2003) Prevalence of the metabolic syndrome in the population of Canary Islands, Spain. Med Clin (Barc) 120, 172-174.

3. Athyros VG, Ganotakis ES, Elisaf M \& Mikhailidis DP (2005) The prevalence of the metabolic syndrome using the National Cholesterol Educational Program and International Diabetes Federation definitions. Curr Med Res Opin 21, 1157-1159.

4. Grundy SM, Cleeman JI, Daniels SR et al:; American Heart Association; National Heart, Lung, and Blood Institute (2005) Diagnosis and management of the metabolic syndrome: an American Heart Association/National Heart, Lung, and Blood Institute Scientific Statement. Circulation 112, 2735-2752.

5. World Health Organization (1999) Definition, diagnosis and classification of diabetes mellitus and its complications. Part 1: Diagnosis and classification of diabetes mellitus. Report of a WHO consultation no. 99.2. Geneva: WHO; available at http://whqlibdoc.who.int/hq/1999/ WHO_NCD_NCS_99.2.pdf

6. Alberti KG, Zimmet P \& Shaw J (2006) Metabolic syndromea new world-wide definition. A consensus statement from the International Diabetes Federation. Diabet Med 23, 469-480.

7. Ford ES, Giles WH \& Dietz WH (2002) Prevalence of the metabolic syndrome among US adults: findings from the Third National Health and Nutrition Examination Survey. JAMA 287, 356-359.

8. The DECODE Study group (2005) Comparison of the three different definitions for the metabolic syndrome in non-diabetic Europeans. Br J Diabetes Vasc Dis 5, $161-168$.

9. Nestel P, Lyu R, Low LP, Sheu WH, Nitiyanant W, Saito I \& Tan CE (2007) Metabolic syndrome: recent prevalence in East and Southeast Asian populations. Asia Pac J Clin Nutr 16, 362-367.

10. Brouwer BG, Visseren FL, van der Graaf Y \& SMART Study Group (2007) The effect of leisure-time physical activity on the presence of metabolic syndrome in patients with manifest arterial disease. The SMART Study. Am Heart $J$ 154, 1146-1152.

11. Alegria E, Cordero A, Laclaustra M, Grima A, Leon M, Casasnovas JA, Luengo E, del Rio A, Ferreira I \& Investigadores del registro MESYAS (2005) Prevalence of 
metabolic syndrome in the Spanish working population: MESYAS Registry. Revista Española de Cardiologia 58, 797-806.

12. Dobbelsteyn CJ, Joffres MR, MacLean DR \& Flowerdew G (2001) A comparative evaluation of waist circumference, waist-to-hip ratio and body mass index as indicators of cardiovascular risk factors. The Canadian Heart Health Surveys. Int J Obes Relat Metab Disord 25, 652-661.

13. Nishida M, Moriyama T, Sugita Y \& Yamauchi-Takihara K (2007) Abdominal obesity exhibits distinct effect on inflammatory and anti-inflammatory proteins in apparently healthy Japanese men. Cardiovasc Diabetol 1, 6-27.

14. Zhu S, St-Onge MP, Heshka S \& Heymsfield SB (2004) Lifestyle behaviors associated with lower risk of having the metabolic syndrome. Metabolism 53, 1503-1511.

15. Narisawa S, Nakamura K, Kato K, Yamada K, Sasaki J \& Yamamoto M (2008) Appropriate waist circumference cutoff values for persons with multiple cardiovascular risk factors in Japan: a large cross-sectional study. J Epidemiol 18, 37-42.

16. Liese AD, Schulz M, Moore CG \& Mayer-Davis EJ (2004) Dietary patterns, insulin sensitivity and adiposity in the Multi-ethnic Insulin Resistance Atherosclerosis Study population. Br J Nutr 92, 973-984.

17. Wirfalt E, Hedblad B, Gullberg B, Mattisson I, Andren C, Rosander U, Janzon L \& Berglund G (2001) Food patterns and components of the metabolic syndrome in men and women: a cross-sectional study within the Malmo Diet and Cancer cohort. Am J Epidemiol 154, 1150-1159.

18. Koh-Banerjee P, Franz M, Sampson L, Liu S, Jacobs DR Jr, Spiegelman D, Willett W \& Rimm E (2004) Changes in wholegrain, bran, and cereal fiber consumption in relation to 8-y weight gain among men. Am J Clin Nutr 80, 1237-1245.

19. Ludwig DS, Pereira MA, Kroenke CH, Hilner JE, Van Horn L, Slattery ML \& Jacobs DR Jr (1999) Dietary fiber, weight gain, and cardiovascular disease risk factors in young adults. JAMA 282, 1539-1546.

20. Liu S, Willett WC, Manson JE, Hu FB, Rosner B \& Colditz G (2003) Relation between changes in intakes of dietary fiber and grain products and changes in weight and development of obesity among middle-aged women. $A m$ J Clin Nutr 78, 920-927.

21. Slavin JL (2005) Dietary fiber and body weight. Nutrition 21, 411-418.

22. Salas-Salvadó J, Farres X, Luque X, Narejos S, Borrell M, Basora J, Anguera A, Torres F, Bullo M, Balanza R \& Fiber in Obesity-Study Group (2008) Effect of two doses of a mixture of soluble fibres on body weight and metabolic variables in overweight or obese patients: a randomised trial. Br J Nutr 99, 1380-1387.

23. Field AE, Willett WC, Lissner L \& Colditz GA (2007) Dietary fat and weight gain among women in the Nurses' Health Study. Obesity 15, 967-976.

24. Koh-Banerjee P, Chu NF, Spiegelman D, Rosner B, Colditz G, Willett W \& Rimm E (2003) Prospective study of the association of changes in dietary intake, physical activity, alcohol consumption, and smoking with 9-y gain in waist circumference among 16587 US men. Am J Clin Nutr 78, 719-727.

25. Bes-Rastrollo M, Sanchez-Villegas A, de la Fuente C, de Irala J, Martinez JA \& Martinez-Gonzalez MA (2006) Olive oil consumption and weight change: the SUN prospective cohort study. Lipids 41, 249-256.

26. Garcia-Lorda P, Megias-Rangil I \& Salas-Salvadó J (2003) Nut consumption, body weight and insulin resistance. Eur J Clin Nutr 57, Suppl. 1, S8-S11.

27. He K, Hu FB, Colditz GA, Manson JE, Willett WC \& Liu S (2004) Changes in intake of fruits and vegetables in relation to risk of obesity and weight gain among middle-aged women. Int J Obes Relat Metab Disord 28, 1569-1574.
28. Vioque J, Weinbrenner T, Castello A, Asensio L \& Garcia de la Hera M (2008) Intake of fruits and vegetables in relation to 10-year weight gain among Spanish adults. Obesity (Silver Spring) 16, 664-670.

29. Bes-Rastrollo M, Sanchez-Villegas A, Gomez-Gracia E, Martinez JA, Pajares RM \& Martinez-Gonzalez MA (2006) Predictors of weight gain in a Mediterranean cohort: the Seguimiento Universidad De Navarra Study 1. Am J Clin Nutr 83, 362-370.

30. Pereira MA, Kartashov AI, Ebbeling CB, Van Horn L, Slattery ML, Jacobs DR Jr \& Ludwig DS (2005) Fastfood habits, weight gain, and insulin resistance (the CARDIA Study): 15-year prospective analysis. Lancet 365 , 36-42.

31. Malik VS, Schulze MB \& Hu FB (2006) Intake of sugarsweetened beverages and weight gain: a systematic review. Am J Clin Nutr 84, 274-288.

32. Mendez MA, Popkin BM, Jakszyn P et al. (2006) Adherence to a Mediterranean diet is associated with reduced 3-year incidence of obesity. J Nutr 136, 2934-2938.

33. Reaven GM (2005) The insulin resistance syndrome: definition and dietary approaches to treatment. Annu Rev Nutr 25, 391-406.

34. McKeown NM, Meigs JB, Liu S, Saltzman E, Wilson PW \& Jacques PF (2004) Carbohydrate nutrition, insulin resistance, and the prevalence of the metabolic syndrome in the Framingham Offspring cohort. Diabetes Care 27, 538-546.

35. Lau C, Faerch K, Glumer C, Tetens I, Pedersen O, Carstensen B, Jorgensen T, Borch-Johnsen K \& Inter99 study (2005) Dietary glycemic index, glycemicload, fiber, simple sugars, and insulin resistance: the Inter99 Study. Diabetes Care 28, 1397-1403.

36. Salmeron J, Ascherio A, Rimm EB, Colditz GA, Spiegelman D, Jenkins DJ, Stampfer MJ, Wing AL \& Willett WC (1997) Dietary fiber, glycemic load, and risk of NIDDM in men. Diabetes Care 20, 545-550.

37. Salmeron J, Manson JE, Stampfer MJ, Colditz GA, Wing AL \& Willett WC (1997) Dietary fiber, glycemic load, and risk of non-insulin-dependent diabetes mellitus in women. JAMA 277, 472-477.

38. Meyer KA, Kushi LH, Jacobs DR Jr, Slavin J, Sellers TA \& Folsom AR (2000) Carbohydrates, dietary fiber, and incident type 2 diabetes in older women. Am J Clin Nutr 71, 921-930.

39. Priebe MG, van Binsbergen JJ, de Vos R \& Vonk RJ (2008) Whole grain foods for the prevention of type 2 diabetes mellitus. Cochrane Database Syst Rev 1, CD006061.

40. Laaksonen DE, Lakka HM, Niskanen LK, Kaplan GA, Salonen JT \& Lakka TA (2002) Metabolic syndrome and development of diabetes mellitus: application and validation of recently suggested definitions of the metabolic syndrome in a prospective cohort study. Am J Epidemiol 156, 1070-1077.

41. Perez-Jimenez F, Lopez-Miranda J, Pinillos MD et al. (2001) A mediterranean and a high-carbohydrate diet improve glucose metabolism in healthy young persons. Diabetologia 44, 2038-2043.

42. Vessby B, Unsitupa M, Hermansen $\mathrm{K}$ et al. \& KANWU Study (2001) Substituting dietary saturated for monounsaturated fat impairs insulin sensitivity in healthy men and women: the KANWU Study. Diabetologia 44, 312-319.

43. Brunner EJ, Wunsch H \& Marmot MG (2001) What is an optimal diet? Relationship of macronutrient intake to obesity, glucose tolerance, lipoprotein cholesterol levels and the metabolic syndrome in the Whitehall II Study. Int J Obes Relat Metab Disord 25, 45-53.

44. Mayer EJ, Newman B, Quesenberry CP Jr \& Selby JV (1993) Usual dietary fat intake and insulin concentrations in healthy women twins. Diabetes Care 16, 1459-1469. 
45. Jiang R, Manson JE, Stampfer MJ, Liu S, Willett WC \& Hu FB (2002) Nut and peanut butter consumption and risk of type 2 diabetes in women. JAMA 288, 2554-2560.

46. Vessby B, Gustafsson IB, Boberg J, Karlstrom B, Lithell H \& Werner I (1980) Substituting polyunsaturated for saturated fat as a single change in a Swedish diet: effects on serum lipoprotein metabolism and glucose tolerance in patients with hyperlipoproteinaemia. Eur J Clin Invest 10, 193-202.

47. Feskens EJ, Bowles CH \& Kromhout D (1991) Inverse association between fish intake and risk of glucose intolerance in normoglycemic elderly men and women. Diabetes Care 14, 935-941.

48. Feskens EJ, Virtanen SM, Rasanen L, Tuomilehto J, Stengard J, Pekkanen J, Nissinen A \& Kromhout D (1995) Dietary factors determining diabetes and impaired glucose tolerance. A 20-year follow-up of the Finnish and Dutch cohorts of the Seven Countries Study. Diabetes Care 18, 1104-1112.

49. Rivellese AA, Maffettone A, Iovine C, Di Marino L, Annuzzi G, Mancini M \& Riccardi G (1996) Long-term effects of fish oil on insulin resistance and plasma lipoproteins in NIDDM patients with hypertriglyceridemia. Diabetes Care 19, 1207-1213.

50. Pereira MA, Jacobs DR Jr, Van Horn L, Slattery ML, Kartashov AI \& Ludwig DS (2002) Dairy consumption, obesity, and the insulin resistance syndrome in young adults: the CARDIA Study. JAMA 287, 2081-2089.

51. van Dam RM, Willett WC, Rimm EB, Stampfer MJ \& Hu FB (2002) Dietary fat and meat intake in relation to risk of type 2 diabetes in men. Diabetes Care 25, 417-424.

52. Mensink RP \& Katan MB (1992) Effect of dietary fatty acids on serum lipids and lipoproteins. A meta-analysis of 27 trials. Arterioscler Thromb 12, 911-919.

53. Jones DY, Judd JT, Taylor PR, Campbell WS \& Nair PP (1987) Influence of caloric contribution and saturation of dietary fat on plasma lipids in premenopausal women. Am J Clin Nutr 45, 1451-1456.

54. Meksawan K, Pendergast DR, Leddy JJ, Mason M, Horvath PJ \& Awad AB (2004) Effect of low and high fat diets on nutrient intakes and selected cardiovascular risk factors in sedentary men and women. J Am Coll Nutr 23, 131-140.

55. Kuusi T, Ehnholm C, Huttunen JK, Kostiainen E, Pietinen P, Leino U, Uusitalo U, Nikkari T, Iacono JM \& Puska P (1985) Concentration and composition of serum lipoproteins during a low-fat diet at two levels of polyunsaturated fat. J Lipid Res 26, 360-367.

56. Brussaard JH, Katan MB, Groot PH, Havekes LM \& Hautvast JG (1982) Serum lipoproteins of healthy persons fed a low-fat diet or a polyunsaturated fat diet for three months. A comparison of two cholesterol-lowering diets. Atherosclerosis 42, 205-219.

57. Brunner D, Weissbort J, Fischer M, Bearman JE, Loebl K, Schwartz S \& Levin S (1979) Serum lipid response to a high-caloric, high-fat diet in agricultural workers during 12 months. Am J Clin Nutr 32, 1342-1349.

58. Nordmann AJ, Nordmann A, Briel M, Keller U, Yancy WS Jr, Brehm BJ \& Bucher HC (2006) Effects of lowcarbohydrate vs low-fat diets on weight loss and cardiovascular risk factors: a meta-analysis of randomized controlled trials. Arch Intern Med 166, 285-293.

59. Turley ML, Skeaff CM, Mann JI \& Cox B (1998) The effect of a low-fat, high-carbohydrate diet on serum high density lipoprotein cholesterol and triglyceride. Eur J Clin Nutr 52, 728-732.

60. Frost G, Leeds AA, Dore CJ, Madeiros S, Brading S \& Dornhorst A (1999) Glycaemic index as a determinant of serum HDL-cholesterol concentration. Lancet 353, $1045-1048$

61. Katan MB (1998) Effect of low-fat diets on plasma highdensity lipoprotein concentrations. Am J Clin Nutr 67, 573S-576S.
62. Aston LM (2006) Glycaemic index and metabolic disease risk. Proc Nutr Soc 65, 125-134.

63. Gerasimova E, Perova N, Ozerova I, Polessky V, Metelskaya V, Sherbakova I, Levachev M, Kulakova S, Nikitin Y \& Astakhova T (1991) The effect of dietary $n-3$ polyunsaturated fatty acids on HDL cholesterol in Chukot residents vs Muscovites. Lipids 26, 261-265.

64. Kris-Etherton PM, Harris WS, Appel LJ \& American Heart Association (2002) Nutrition Committee. Fish consumption, fish oil, omega-3 fatty acids, and cardiovascular disease. Circulation 106, 2747-2757.

65. Skulas-Ray AC, West SG, Davidson MH \& Kris-Etherton PM (2008) Omega-3 fatty acid concentrates in the treatment of moderate hypertriglyceridemia. Expert Opin Pharmacother 9, 1237-1248.

66. Ellison RC, Zhang Y, Qureshi MM, Knox S, Arnett DK, Province MA \& investigators of the NHLBI Family Heart Study (2004) Lifestyle determinants of high-density lipoprotein cholesterol: The National Heart, Lung, and Blood Institute Family Heart Study. Am Heart J 147, 529-535.

67. Rimm EB, Williams P, Fosher K, Criqui M \& Stampfer MJ (1999) Moderate alcohol intake and lower risk of coronary heart disease: meta-analysis of effects on lipids and haemostatic factors. BMJ 319, 1523-1528.

68. Geleijnse JM, Kok FJ \& Grobbee DE (2003) Blood pressure response to changes in sodium and potassium intake: a meta-regression analysis of randomised trials. $J$ Hum Hypertens 17, 471-480.

69. He FJ \& MacGregor GA (2002) Effect of modest salt reduction on blood pressure: a meta-analysis of randomized trials. Implications for public health. J Hum Hypertens 16, 761-770.

70. Mizushima S, Cappuccio FP, Nichols R \& Elliott P (1998) Dietary magnesium intake and blood pressure: a qualitative overview of the observational studies. I Hum Hypertens 12, 447-453.

71. Karppanen H, Karppanen P \& Mervaala E (2005) Why and how to implement sodium, potassium, calcium, and magnesium changes in food items and diets? J Hum Hypertens 19, Suppl. 3, S10-S19.

72. Jee SH, Miller 3rd ER, Guallar E, Singh VK, Appel LJ \& Klag MJ (2002) The effect of magnesium supplementation on blood pressure: a meta-analysis of randomized clinical trials. Am J Hypertens 15, 691-696.

73. Dickinson HO, Nicolson DJ, Campbell F, Cook JV, Beyer FR, Ford GA \& Mason J (2006) Magnesium supplementation for the management of essential hypertension in adults. Cochrane Database Syst Rev 3, CD004640.

74. Allender PS, Cutler JA, Follmann D, Cappuccio FP, Pryer J \& Elliott P (1996) Dietary calcium and blood pressure: a meta-analysis of randomized clinical trials. Ann Intern Med 124, 825-831.

75. Alonso A, Beunza JJ, Delgado-Rodríguez M, Martínez JA \& Martínez-González MA (2005) Low-fat dairy consumption and reduced risk of hypertension: the Seguimiento Universidad de Navarra (SUN) cohort. Am J Clin Nutr 82, 972-979.

76. Toledo E, Delgado-Rodriguez M, Estruch R et al. (2009) Low-fat dairy products and blood pressure: follow-up of 2290 older persons at high cardiovascular risk participating in the PREDIMED Study. Br J Nutr 101, 59-67.

77. Merisel H (2005) Biochemical properties of peptides encrypted in bovine milk proteins. Curr Med Chem 12, 1905-1919.

78. Appel LJ, Moore TJ, Obarzanek E et al. (1997) A clinical trial of the effects of dietary patterns on blood pressure. DASH collaborative research group. $N$ Engl J Med 336, 1117-1124.

79. Lien LF, Brown AJ, Ard JD et al. (2007) Effects of PREMIER lifestyle modifications on participants with and without the metabolic syndrome. Hypertension 50, 609-616. 
80. Panagiotakos DB, Pitsavos C \& Stefanadis C (2006) Dietary patterns: a Mediterranean diet score and its relation to clinical and biological markers of cardiovascular disease risk. Nutr Metab Cardiovasc Dis 16, 559-568.

81. Psaltopoulou T, Naska A, Orfanos P, Trichopoulos D, Mountokalakis T \& Trichopoulou A (2004) Olive oil, the Mediterranean diet, and arterial blood pressure: the Greek European Prospective Investigation into Cancer and Nutrition (EPIC) Study. Am J Clin Nutr 80, 1012-1018.

82. Alonso A \& Martinez-Gonzalez MA (2004) Olive oil consumption and reduced incidence of hypertension: the SUN Study. Lipids 39, 1233-1238.

83. Rasmussen BM, Vessby B, Uusitupa M, Berglund L, Pedersen E, Riccardi G, Rivellese AA, Tapsell L, Hermansen K \& the KANWU Study Group (2006) Effects of dietary saturated, monounsaturated, and $n$ - 3 fatty acids on blood pressure in healthy subjects. Am J Clin Nutr 83, 221-226.

84. Mensink RP, Janssen MC \& Katan MB (1988) Effect on blood pressure of two diets differing in total fat but not in saturated and polyunsaturated fatty acids in healthy volunteers. Am J Clin Nutr 47, 976-980.

85. Ferrara LA, Raimondi AS, d'Episcopo L, Guida L, Dello Russo A \& Marotta T (2000) Olive oil and reduced need for antihypertensive medications. Arch Intern Med 160 , $837-842$

86. Burns J, Gardner PT, O'Neil J et al. (2000) Relationship among antioxidant activity, vasodilation capacity, and phenolic content of red wines. J Agric Food Chem 48, 220-230.

87. Brenn T (1986) The Tromso Heart Study: alcoholic beverages and coronary risk factors. I Epidemiol Community Health 40, 249-256.

88. Bulpitt CJ, Shipley MJ \& Semmence A (1987) The contribution of a moderate intake of alcohol to the presence of hypertension. J Hypertens 5, 85-91.

89. Zilkens RR, Burke V, Hodgson JM, Barden A, Beilin LJ \& Puddey IB (2005) Red wine and beer elevate blood pressure in normotensive men. Hypertension 45, 874-879.

90. Harris TB, Ferrucci L, Tracy RP, Corti MC, Wacholder S, Ettinger Jr WH, Heimovitz H, Cohen HJ \& Wallace R (1999) Associations of elevated interleukin-6 and Creactive protein levels with mortality in the elderly. Am J Med 106, 506-512.

91. Danesh J, Wheeler JG, Hirschfield GM, Eda S, Eiriksdottir G, Rumley A, Lowe GD, Pepys MB \& Gudnason V (2004) C-reactive protein and other circulating markers of inflammation in the prediction of coronary heart disease. N Engl J Med 350, 1387-1397.

92. Sattar N, Gaw A, Scherbakova O et al. (2003) Metabolic syndrome with and without C-reactive protein as a predictor of coronary heart disease and diabetes in the West of Scotland Coronary Prevention Study. Circulation 108, 414-419.

93. Ridker PM, Buring JE, Cook NR \& Rifai N (2003) C-reactive protein, the metabolic syndrome, and risk of incident cardiovascular events: an 8-year follow-up of 14719 initially healthy American women. Circulation 107, 391-397.

94. Rutter MK, Meigs JB, Sullivan LM, D'Agostino RB Sr \& Wilson PW (2004) C-reactive protein, the metabolic syndrome, and prediction of cardiovascular events in the Framingham Offspring Study. Circulation 110, 380-385.

95. Pischon T, Hu FB, Rexrode KM, Girman CJ, Manson JE \& Rimm EB (2008) Inflammation, the metabolic syndrome, and risk of coronary heart disease in women and men. Atherosclerosis 197, 392-399.

96. Estruch R, Sacanella E, Badia E, Antunez E, Nicolas JM, Fernandez-Sola J, Rotilio D, de Gaetano G, Rubin E \& Urbano-Marquez A (2004) Different effects of red wine and gin consumption on inflammatory biomarkers of atherosclerosis: a prospective randomized crossover-trial. Effects of wine on inflammatory markers. Atherosclerosis 175, 117-123.

97. Ros E, Nunez I, Perez-Heras A, Serra M, Gilabert R, Casals E \& Deulofeu R (2004) A walnut diet improves endothelial function in hypercholesterolemic subjects: a randomized crossover trial. Circulation 109, 1609-1614.

98. Jensen MK, Koh-Banerjee P, Franz M, Sampson L, Gronbaek M \& Rimm EB (2006) Whole grains, bran, and germ in relation to homocysteine and markers of glycemic control, lipids, and inflammation 1. Am J Clin Nutr 83, 275-283.

99. Chrysohoou C, Panagiotakos DB, Pitsavos C, Das UN \& Stefanadis C (2004) Adherence to the Mediterranean diet attenuates inflammation and coagulation process in healthy adults: the ATTICA Study. J Am Coll Cardiol 44, 152-158.

100. Esposito K, Marfella R, Ciotola M, Di Palo C, Giugliano F, Giugliano G, D'Armiento M, D'Andrea F \& Giugliano D (2004) Effect of a Mediterranean-style diet on endothelial dysfunction and markers of vascular inflammation in the metabolic syndrome: a randomized trial. JAMA 292, 1440-1446.

101. Dai J, Miller AH, Bremner JD et al. (2008) Adherence to the Mediterranean diet is inversely associated with circulating interleukin-6 among middle-aged men: a twin study. Circulation 117, 169-175.

102. Michalsen A, Lehmann N, Pithan C, Knoblauch NT, Moebus S, Kannenberg F, Binder L, Budde T \& Dobos GJ (2006) Mediterranean diet has no effect on markers of inflammation and metabolic risk factors in patients with coronary artery disease. Eur J Clin Nutr 60, 478-485.

103. Estruch R, Martinez-Gonzalez MA, Corella D et al. \& PREDIMED Study investigators (2006) Effects of a Mediterranean-style diet on cardiovascular risk factors: a randomized trial. Ann Intern Med 145, 1-11.

104. Fitó M, Guxens M, Corella D et al:; for the PREDIMED Study investigators (2007) Effect of a traditional Mediterranean diet on lipoprotein oxidation: a randomized controlled trial. Arch Intern Med 167, 1195-1203.

105. Esposito K, Ciotola M \& Giugliano D (2007) Mediterranean diet and the metabolic syndrome. Mol Nutr Food Res 51, 1268-1274.

106. Jacques PF \& Tucker KL (2001) Are dietary patterns useful for understanding the role of diet in chronic disease? $\mathrm{Am} \mathrm{J}$ Clin Nutr 73, 1-2.

107. López EP, Rice C, Weddle DO \& Rahill GJ (2008) The relationship among cardiovascular risk factors, diet patterns, alcohol consumption, and ethnicity among women aged 50 years and older. I Am Diet Assoc 108, 248-256.

108. Newby PK, Muller D \& Tucker KL (2004) Associations of empirically derived eating patterns with plasma lipid biomarkers: a comparison of factor and cluster analysis methods. Am J Clin Nutr 80, 759-767.

109. Newby PK, Muller D, Hallfrisch J, Andres R \& Tucker KL (2004) Food patterns measured by factor analysis and anthropometric changes in adults. Am J Clin Nutr 80, 504-513.

110. Fung TT, Schulze M, Manson JE, Willett WC \& Hu FB (2004) Dietary patterns, meat intake, and the risk of type 2 diabetes in women. Arch Intern Med 164, 2235-2240.

111. Babio N, Bulló M, Basora J, Martínez-González MA, Fernández-Ballart J, Márquez-Sandoval F, Molina C \& Salas-Salvadó J; on behalf of the Nureta-PREDIMED investigators (2009) Adherence to the Mediterranean diet and risk of metabolic syndrome and its components. Nutr Metab Cardiovasc Dis (Epub ahead of print).

112. Salas-Salvadó J, Fernández-Ballart J, Ros E et al.; on behalf of the PREDIMED Study investigators (2008) A Mediterranean diet supplemented with nuts improves metabolic syndrome status. One-year results of the PREDIMED randomized trial. Arch Intern Med 168, 2449-2458. 
113. Esmaillzadeh A, Kimiagar M, Mehrabi Y, Azadbakht L, Hu FB \& Willett WC (2007) Dietary patterns, insulin resistance, and prevalence of the metabolic syndrome in women. Am J Clin Nutr 85, 910-918.

114. Tortosa A, Bes-Rastrollo M, Sanchez-Villegas A, BasterraGortari FJ, Nunez-Cordoba JM \& Martinez-Gonzalez MA (2007) Mediterranean diet inversely associated with the incidence of metabolic syndrome: the SUN prospective cohort. Diabetes Care 30, 2957-2959.

115. Panagiotakos DB, Pitsavos C, Chrysohoou C, Skoumas J, Tousoulis D, Toutouza M, Toutouzas P \& Stefanadis C (2004) Impact of lifestyle habits on the prevalence of the metabolic syndrome among Greek adults from the ATTICA study. Am Heart J 147, 106-112.

116. Williams DE, Prevost AT, Whichelow MJ, Cox BD, Day NE \& Wareham NJ (2000) A cross-sectional study of dietary patterns with glucose intolerance and other features of the metabolic syndrome. Br J Nutr 83, 257-266.

117. Lutsey PL, Steffen LM \& Stevens J (2008) Dietary intake and the development of the metabolic syndrome: the
Atherosclerosis Risk in Communities Study. Circulation 117, 754-761.

118. Azadbakht L, Mirmiran P, Esmaillzadeh A, Azizi T \& Azizi F (2005) Beneficial effects of a dietary approaches to stop hypertension eating plan on features of the metabolic syndrome. Diabetes Care 28, 2823-2831.

119. van Dam RM, Grievink L, Ocke MC \& Feskens EJ (2003) Patterns of food consumption and risk factors for cardiovascular disease in the general Dutch population. Am J Clin Nutr 77, 1156-1163.

120. Vincent-Baudry S, Defoort C, Gerber M et al. (2005) The Medi-RIVAGE Study: reduction of cardiovascular disease risk factors after a 3-mo intervention with a mediterranean-type diet or a low-fat diet. Am J Clin Nutr 82, 964-971.

121. Gastaldi M, Diziere S, Defoort C, Portugal H, Lairon D, Darmon M \& Planells R (2007) Sex-specific association of fatty acid binding protein 2 and microsomal triacylglycerol transfer protein variants with response to dietary lipid changes in the 3-mo Medi-RIVAGE Primary Intervention Study. Am J Clin Nutr 86, 1633-1641. 